\title{
Antimalarial drugs disrupt ion homeostasis in malarial parasites
}

\author{
Marcos L Gazarini, Carlos AO Sigolo, Regina P Markus, Andrew P Thomas*, \\ Célia RS Garcia/ ${ }^{+}$
}

\begin{abstract}
Departamento de Fisiologia, Instituto de Biociências, Universidade de São Paulo, Rua do Matão, travessa 14, nº 321, 05508-900 São Paulo, SP, Brasil *Department of Pharmacology and Physiology, University of Medicine and Dentistry of New Jersey, Newark, New Jersey, US
\end{abstract}

Plasmodium chabaudi malaria parasite organelles are major elements for ion homeostasis and cellular signaling and also target for antimalarial drugs. By using confocal imaging of intraerythrocytic parasites we demonstrated that the dye acridine orange $(A O)$ is accumulated into P. chabaudi subcellular compartments. The $A O$ could be released from the parasite organelles by collapsing the $\mathrm{pH}$ gradient with the $\mathrm{K}^{+} / \mathrm{H}^{+}$ionophore nigericin $(20 \mu \mathrm{M})$, or by inhibiting the $H^{+}$-pump with bafilomycin $(4 \mu \mathrm{M})$. Similarly, in isolated parasites loaded with calcium indicator Fluo 3-AM, bafilomycin caused calcium mobilization of the acidic calcium pool that could also be release with nigericin. Interestingly after complete release of the acidic compartments, addition of thapsigargin at $10 \mu \mathrm{M}$ was still effective in releasing parasite intracellular calcium stores in parasites at trophozoite stage. The addition of antimalarial drugs chloroquine and artemisinin resulted in $A O$ release from acidic compartments and also affected maintenance of calcium in ER store by using different drug concentrations.

Key words: malaria - Plasmodium chabaudi - calcium - chloroquine - artemisinin - acidic compartment

During the course of its intraerythocytic life, Plasmodium causes well documented biochemical and morphological changes in both pathogen and host cell (Howard 1982, Coppel 1986, Garcia et al. 1997, Kirk 2001). Acidic compartments are organelles present in Plasmodium and several trypanosomatids (Docampo \& Moreno 2001). For Plasmodium, it has been suggested that these organelles are the food vacuole in which hemoglobin is digested and antimalarial drugs such as chloroquine are accumulated (Yayon et al. 1984). Chloroquine is though to act by preventing the monomeric hemin from forming the inert and insoluble polymer hemozoin which is derived from digestion of hemoglobin in the acidic vacuole (Slater \& Ceram 1992). Defining the sites of chloroquine action in Plasmodium, as well as determining how it is related to proton activity in the acidic compartment is of major importance in the physiology of these parasites.It has been reported that the antimalarial artemisinin act on PfATP6 $\left(\mathrm{Ca}^{2+}\right.$ ATPase $)$ in $P$. falciparum, thus affecting Plasmodium $\mathrm{Ca}^{2+}$ homeostasis (Uhlemann et al. 2005).

Regulation of internal $\mathrm{pH}$ is important to parasite survival as this sets the environment for intracellular enzymes to function. It has been reported that $P$. falciparum and $P$. chabaudi extrude $\mathrm{H}^{+}$to the extracellular medium by a $\mathrm{Na}^{+}$independent mechanism (Saliba \&

Financial support: Fapesp, $\mathrm{CNPq}$

+Corresponding author: cgarcia@usp.br

Receive 8 February 2007

Accepted 14 May 2007
Kirk 1999). Other mechanisms for $\mathrm{pH}$ regulation described in malaria parasites may involve the $\mathrm{V}-\mathrm{H}^{+}-\mathrm{AT}-$ Pase and the $\mathrm{V}-\mathrm{H}^{+}$-PPase in acidocalcisomes (Marchesini et al. 2000, McIntosh \& Vaidya 2002, Saliba et al. 2003, Biagini et al. 2003). We have reported the existence of $\mathrm{Ca}^{2+}$ pools in the acidic compartment of rodent as well as human malaria parasites as a possible mechanism for the regulation of calcium concentration in these parasites (Garcia et al. 1998, Passos \& Garcia 1998). Calcium homeostasis in malaria parasites has been extensively studied by several authors (Tanabe et al. 1982, Krungkrai \& Yuthavong 1983, Scheibel et al. 1987, Wasserman et al. 1990, Adovelande et al. 1993, Garcia et al. 1997, 1998, Gazarini et al. 2003, Gazarini \& Garcia 2004, Beraldo et al, 2005, Budu et al. 2007). Interestingly, in $P$. chabaudi, the second messenger $\mathrm{IP}_{3}$, mobilizes $\mathrm{Ca}^{2+}$ not only from the classical ER-like pool but also from an acidic compartment, implying that these parasites utilize a calcium-mediated cell signaling mechanism similar to higher organisms (Passos \& Garcia 1998). Nevertheless, we still have no clear picture of signaling events and the role of the acidic compartment in malaria parasite signaling, or its significance in the therapeutic actions of antimalarial drugs such as chloroquine (Yayon et al. 1984, Dzekunov et al. 2000). $\mathrm{Ca}^{2+}$ and $\mathrm{pH}$ changes are crucial for parasite enzyme activity such as proteases (Na et al. 2004, Farias et al. 2005).

In this context, understanding the mechanisms utilized by Plasmodium for the maintenance of its ion homeostasis is crucial. In the present work, we have studied the physiological mechanisms by which $\mathrm{H}^{+}$and $\mathrm{Ca}^{2+}$ activity are related in the acidic compartments of $P$. chabaudi, and how these are affected by the antimalarials chloroquine and artemisinin. Unraveling the mechanisms by which these organelles contribute to cell function may be important for developing alternative strategies for therapeutic approaches to malaria. 


\section{MATERIALS AND METHODS}

P. chabaudi parasites - Synchronous parasitemia by P. chabaudi (clone AJ) was maintained in female mice $(\mathrm{Balb} / \mathrm{c})$ by transfer of infection. Parasitemia was about $50 \%$. After collecting the blood, cells were washed with PBS (137 mM NaCl, $2.7 \mathrm{mM} \mathrm{KCl,} 4.3 \mathrm{mM} \mathrm{Na}_{2} \mathrm{HPO}_{4}, 1.4$ $\mathrm{mM} \mathrm{NaH} 2 \mathrm{PO}_{4}$ and $1 \mathrm{mM} \mathrm{CaCl}_{2}$ ) and leucocytes and platelets were removed by a powdered cellulose column. Parasitemia was determined from Giemsa-stained thin films.

Parasite isolation - The infected RBCs were then washed twice by centrifugation at $1500 \mathrm{~g}$ for $7 \mathrm{~min}$ in PBS. Infected RBC $\left(10^{7} \mathrm{ml}^{-1}\right)$ was lysed in PBS with 60 $\mu \mathrm{g} . \mathrm{ml}^{-1}$ saponin. RBC membranes were removed by centrifugation $\left(9000 \mathrm{~g}\right.$ for $10 \mathrm{~min}$ at $\left.4^{\circ} \mathrm{C}\right)$, the parasites were washed twice in MOPS buffer $(116 \mathrm{mM} \mathrm{NaCl}, 5.4 \mathrm{mM}$ $\mathrm{KCl}, 0.8 \mathrm{mM} \mathrm{MgSO}_{4}, 5.5 \mathrm{mM}$ D-glucose, $50 \mathrm{mM}$ MOPS, and $2 \mathrm{mM} \mathrm{CaCl}_{2}, \mathrm{pH} 7.2$ ) and dispensed in the same buffer at room temperature (Passos \& Garcia 1998).

Confocal microscopy - In vitro parasite-infected RBCs $\left(10^{6}\right.$ cells $\left.\mathrm{ml}^{-1}\right)$ were loaded with acridine orange (AO) $(5 \mu \mathrm{M})$ for $5 \mathrm{~min}$ at room temperature and washed once with MOPS buffer as described above. Cells were resuspended in the same buffer and placed in a microscopy chamber. The data acquisition was performed with Zeiss confocal microscope (LSM 510) using the LSM 510 software, version 2.5; excitation $488 \mathrm{~nm}$ (Argon laser) and emission collected with a bandpass filter of 505-550 nm (Fluo3-AM). Calcium measurements were performed with isolated parasites incubated with Fluo-3 AM $(5 \mu \mathrm{M})$ for $50 \mathrm{~min}$ at $37^{\circ} \mathrm{C}$ and placed in microscopy chambers at room temperature. The configurations for image acquisition were the EX $488 \mathrm{~nm}$ and $\mathrm{Em}>560 \mathrm{~nm}$ for $\mathrm{AO}$ measurements. Software-based analysis allowed fluorescence imaging in the whole field of view or in a selected cell as a function of time. This was accomplished by defining areas of interest on a given image frame and requesting the software to construct a graphical representation of intensity against time.

Experiments were carried out with at least three different cell preparations. Traces represent typical single cell responses unless indicated otherwise.

Spectrofluorimetric measurement - Isolated parasites $\left(10^{7}\right.$ cells $\left.\mathrm{ml}^{-1}\right)$ were incubated with MOPS buffer in $2 \mathrm{ml}$ cuvette. The measurements were performed in a Shimadzu RF-5301 PC spectrofluorimeter at $37^{\circ} \mathrm{C}$ and dyes fluorescence (Fluo-3 AM and AO) was measured continuously after the drug addition. Parasites were incubated with calcium indicator Fluo-3 AM $(5 \mu \mathrm{M})$ for $50 \mathrm{~min}$ at $37^{\circ} \mathrm{C}$ in MOPS buffer containing $2 \mathrm{mM} \mathrm{CaCl}_{2}$ and probenecid $(40 \mu \mathrm{M})$ or $\mathrm{AO}(5 \mu \mathrm{M})$ incubated for 5 $\min$ at $37^{\circ} \mathrm{C}$ in the same buffer. The dyes parameters are excitation $490 \mathrm{~nm}$ and emission collected at $530 \mathrm{~nm}$ for Fluo-3 AM and AO fluorescence measurement was obtained with Ex-495 nm/Em-590 nm.

Extracellular $H^{+}$levels - The effect of chloroquine on $\mathrm{H}^{+}$mobilization in isolated parasites was recorded using a Cytosensor microphysiometer (Mol Devices, US), a silicon-based biosensor system. This instrument continuously monitors the extracellular $\mathrm{pH}$ surrounding cells in culture, and reports cell activation by measuring the increases in extracellular acidification rate occurring in response to agonist stimulation (McConnell et al. 1992). The isolated parasites was resuspended in DMEM (GIBCO) plus $30 \%$ agarose to improve parasites adherence onto the polycarbonate membrane of the transwell capsules $(3 \mu \mathrm{m}$ pore size) at a density of $2.5 \times 10^{5}$ cells.

\section{RESULTS}

We have investigated the dynamics of solute exchange in the acidic compartments of isolated and intact bloodstage malaria parasite, $P$. chabaudi. To study intracellular $\mathrm{pH}$ changes, we loaded infected red blood cells at trophozoite stage ( $P$. chabaudi) with AO. Dye mobilization through compartments was measured by selecting areas of interest (cytosol and acid compartment) by confocal imaging (Fig. 1). Addition of $\mathrm{H}^{+}$-ATPase inhibitor bafilomycin $(4 \mathrm{mM})$ to the cells led to alkalinization of acidic compartments as indicated by the partial release of accumulated AO (Fig. 1A), and simultaneously increases the cytosol fluorescence (Fig. 1B). The remaining $\mathrm{AO}$ could be released by addition of the $\mathrm{K}^{+} / \mathrm{H}^{+}$ionophore nigericin to the cells $(20 \mu \mathrm{M})$, which totally released the compartmentalized AO fluorescence (Fig. 1C). Dose-dependent addition of bafilomycin promotes the depletion of AO stores. A remarkable (over 90\%) release of AO fluorescence occurs with addition of bafilomycin at $10 \mu \mathrm{M}$ (Fig. 1D).

The effect of the antimalarial chloroquine on $\mathrm{AO}$ accumulation in subcellular compartments (Fig. 2A) in infected erythrocyte (Fig. 2B) shows that chloroquine (80 $\mu \mathrm{M})$ promotes extrusion of $\mathrm{AO}$ from the acidic compartments, presumably as a result of alkalinization. The subsequent addition of $\mathrm{H}^{+}$-ATPase inhibitor bafilomycin $(4 \mu \mathrm{M})$ caused complete depletion of the residual AO from the acidic compartments (Fig. 2C). Taken together, the data of Figs 1 and 2 suggest that $P$. chabaudi parasites display a bafilomycin-sensitive acidic compartment that can be affected in a dose-dependent manner and is also a target for chloroquine.

By using spectrofluorimeter measurements and isolated parasites $\left(10^{7}\right.$ cells $)$ at trophozoite stage previously incubated with $\mathrm{AO}(5 \mu \mathrm{M})$ for $5 \mathrm{~min} / 37^{\circ} \mathrm{C}$ we showned that $\mathrm{AO}$ could be released in a dose-dependent manner by addition of artemisinin and chloroquine (Fig. 3).

We have previously demonstrated that the $\mathrm{H}^{+}$-pump inhibitor 7-chloro-4-nitrobenz-2-oxa-1,3-diazole (NBD$\mathrm{Cl}$ ) caused release of $\mathrm{Ca}^{2+}$ in Fluo-3 loaded P. falciparum parasites (Garcia et al. 1998). We therefore investigated the effects of the more selective $\mathrm{H}^{+}$-pump inhibitor, bafilomycin on $\mathrm{Ca}^{2+}$ homeostasis. We measured the fluorescence changes in isolated parasites (trophozoite stage) loaded with the calcium probe Fluo-3 AM $(5 \mu \mathrm{M})$ and placed to microscopy microplates for confocal measurements, in response to effectors of the acidic compartments. Using different concentration of bafilomycin, we observed that bafilomycin-sensitive $\mathrm{Ca}^{2+}$ pool is completely discharged at $4 \mu \mathrm{M}$ (Fig. 4A). However subsequent addition of nigericin $(20 \mu \mathrm{M})$ after bafilomycin treatment $(4 \mu \mathrm{M})$ reveals a subsequent $\mathrm{Ca}^{2+}$ rise (Fig. $4 \mathrm{~B})$. As nigericin was able to release the entire $\mathrm{Ca}^{2+}$ pool by itself further addition of bafilomycin had no effect 

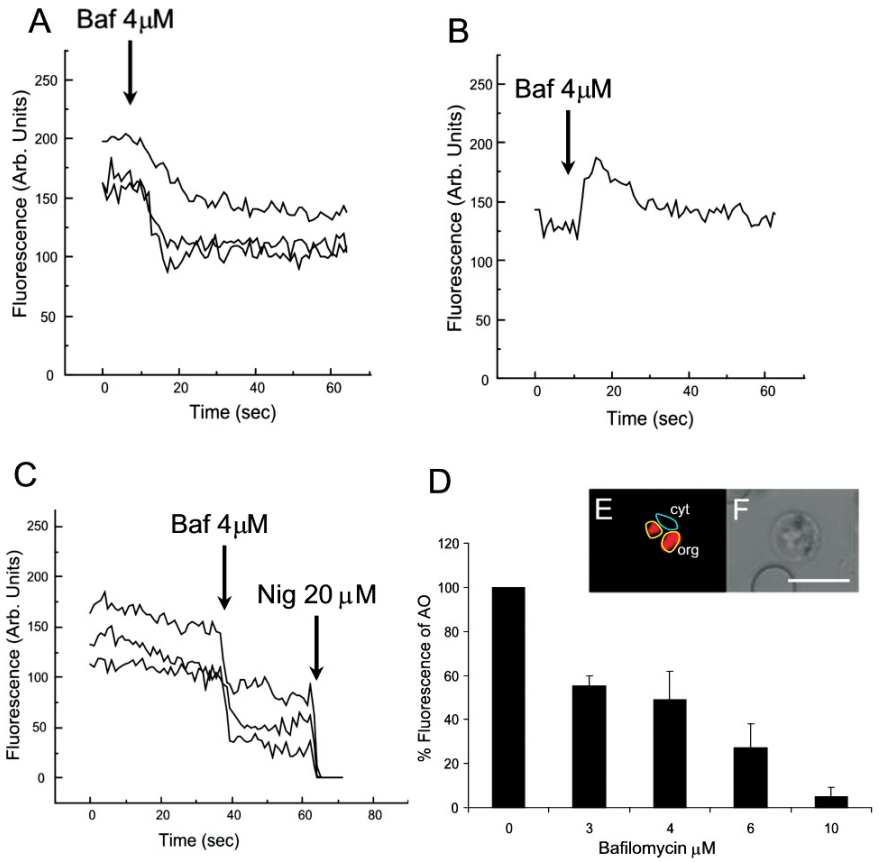

Fig. 1: effect of the $\mathrm{H}^{+}$pump inhibitor bafilomycin on Plasmodium chabaudi within the intact RBC. Infected $\mathrm{RBC}$ was loaded with $\mathrm{AO}(5 \mu \mathrm{M})$ as described in the Methods Section. A: effect of bafilomycin (Baf) $(4 \mu \mathrm{M})$ on organelles selected areas stained with AO in single cell; B: cytosolic area with acidification promoted by bafilomycin; C: Bafilomycin and nigericin (Nig) effect on subcellular areas; D: dose-response effect of bafilomycin on AO release from intracellular stores; E: fluorescence imaging with selected areas (cytosol and organelles); F: phase contrast. *(D) bar plot represent $\%$ of control fluorescence (arbitrary units) remaining from ten cells in three different trials. Scale bar of $10 \mu \mathrm{m}$.

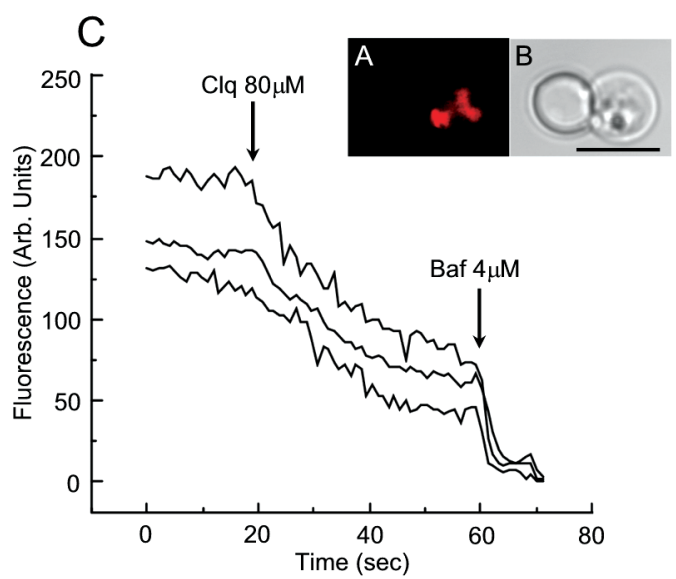

Fig. 2: action of the antimalarial chloroquin and bafilomycin on acidic compartments in Plasmodium chabaudi. Infected RBC loaded with $5 \mu \mathrm{M}$ AO; A: fluorescence image; B: phase contrast; $\mathrm{C}$ : changes in AO fluorescence (arbitrary units) in selected subcellular compartments promoted by chloroquine $(\mathrm{Clq})(80 \mu \mathrm{M})$. Scale bar of $10 \mu \mathrm{m}$.

on $\mathrm{Ca}^{2+}$ release (Fig. 4C). Interestingly, neither bafilomycin (Fig. 4D) or nigericin (Fig. 4E) was able to deplete ER Ca ${ }^{2+}$ pool, as a subsequent addition of thapsigargin (Thg) promoted a second calcium rise.

To investigate the effect of the antimalarials drugs chloroquine and artemisinin in calcium homeostasis we

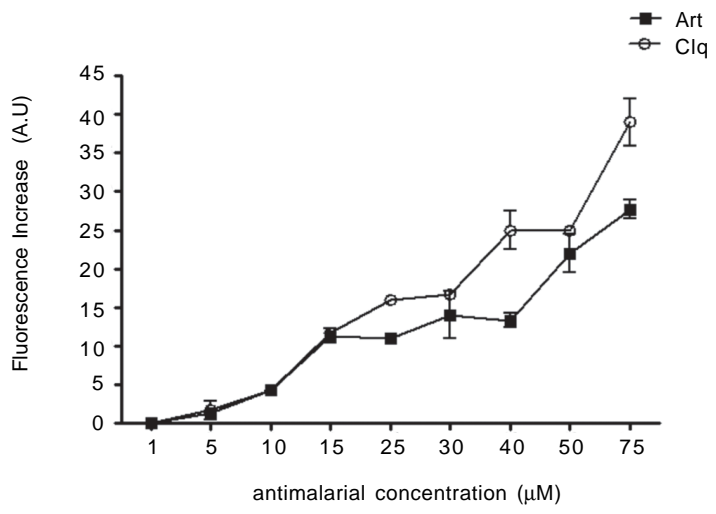

Fig. 3: effect of antimalarial drugs chloroquine and artemisinin on acridine orange mobilization from acidic compartment. Isolated parasites loaded with $5 \mu \mathrm{M}$ AO for $5 \mathrm{~min}$. Different concentrations of drugs (Artartemisinin and Clq-chloroquine) were added and fluorescence measurement was performed in spectrofluorimeter cuvette. Fluorescence intensities (arbitrary units - AU) represent at least three different cell preparations.

carried out experiments with isolated parasites loaded with calcium indicator Fluo-3 AM $(5 \mu \mathrm{M})$. Fig 5 shows spectrofluorimetric measurements of calcium release by Thg $(10 \mu \mathrm{M})$ with parasites previously incubated (15 min at $37^{\circ} \mathrm{C}$ ) with different concentrations of chloroquine and artemisinin $(0-80 \mu \mathrm{M})$ in a high calcium ex- 

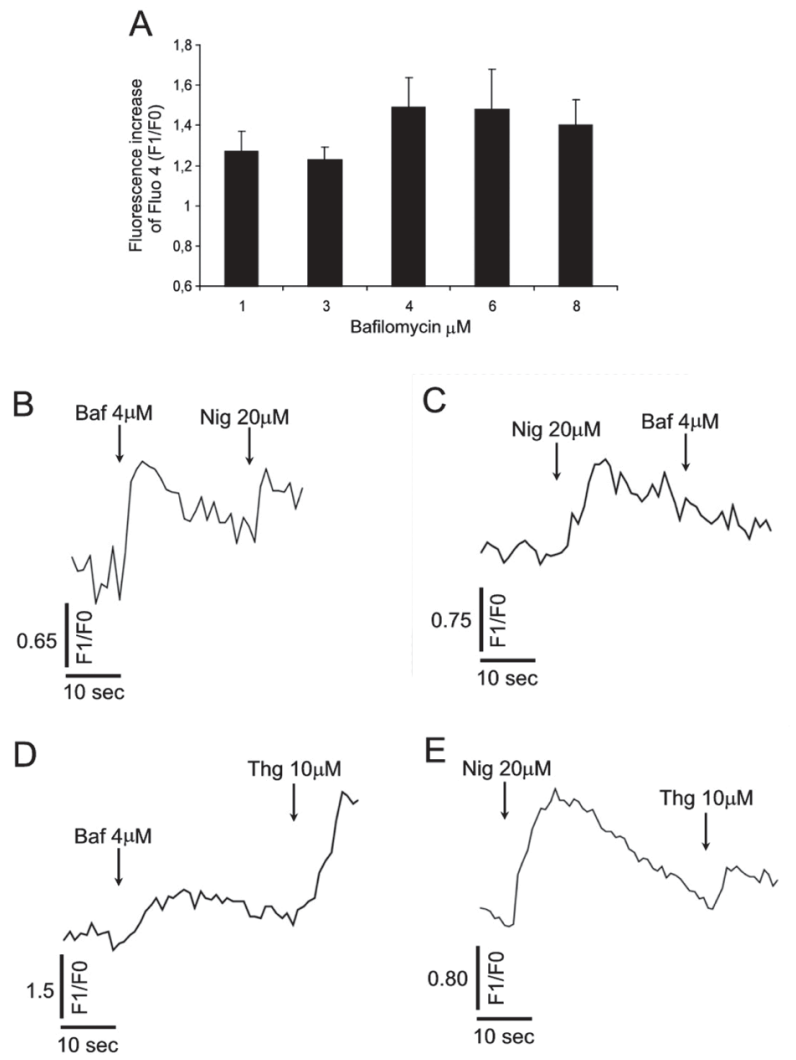

Fig. 4: $\mathrm{H}^{+}$pump inhibitor-bafilomycin induces $\mathrm{Ca}^{2+}$ release in intact Plasmodium chabaudi parasites. $P$. chabaudi parasites were loaded with the calcium indicator Fluo-3 AM $(5 \mu \mathrm{M})$ as described in the Methods Section and cytosolic fluorescence intensities measured in confocal microscopy were normalized as (F1-maximal fluorescence after drug addition/F0-fluorescence before drug addition). A: dose-response effect of bafilomycin (Baf) on cytosolic calcium fluorescence (mean data of fluorescence ratio remaining from ten cells in three different trials); $\mathrm{B}$ : addition of bafilomycin (increase of $1.3 \pm 0.1 ; \mathrm{n}=6)$ and nigericin (Nig) $(20 \mu \mathrm{M})$; C: addition of nigericin $(1.42 \pm 0.1 ; \mathrm{n}=6)$ and bafilomycin $(4 \mu \mathrm{M})$; D: addition of bafilomycin $(1.5 \pm 0.2 ; n=6)$ and thapsigargin (Thg) $(10 \mu \mathrm{M})$; E: addition of nigericin $(1.65 \pm 0.3 ; \mathrm{n}=6)$ and thapsigargin $(10 \mu \mathrm{M})$.

tracellular medium (2 $\mathrm{mM})$. The results show that previous parasite incubation with chloroquine or artemisinin leads to a dose-dependent reduction of total amount of calcium release by thapsigargin.

When parasites are exposed to chloroquine, the cytosolic $\mathrm{pH}$ decrease as a result of extrusion of $\mathrm{H}^{+}$from acidic compartments and the parasites ( $P$. falciparum) try to restore the cytosolic $\mathrm{pH}$ level using plasma membrane mechanisms (Saliba \& Kirk 1999, Marchesini et al. 2000, Saliba et al. 2003). By using microphysiometry we showed that addition of chloroquine to $P$. chabaudi at the trophozoite stage led to a dose-dependent increase in the extracellular acidification rate (Fig. 6). The mean $50 \%$ maximal effective concentration $\left(\mathrm{EC}_{50}\right)$ for three experiments was $16.29 \pm 0.4 \mu \mathrm{M}(\mathrm{n}=3)$ of chloroquine. This data reveal an activation of plasma membrane mechanism of $\mathrm{H}^{+}$extrusion under chloroquine treatment.

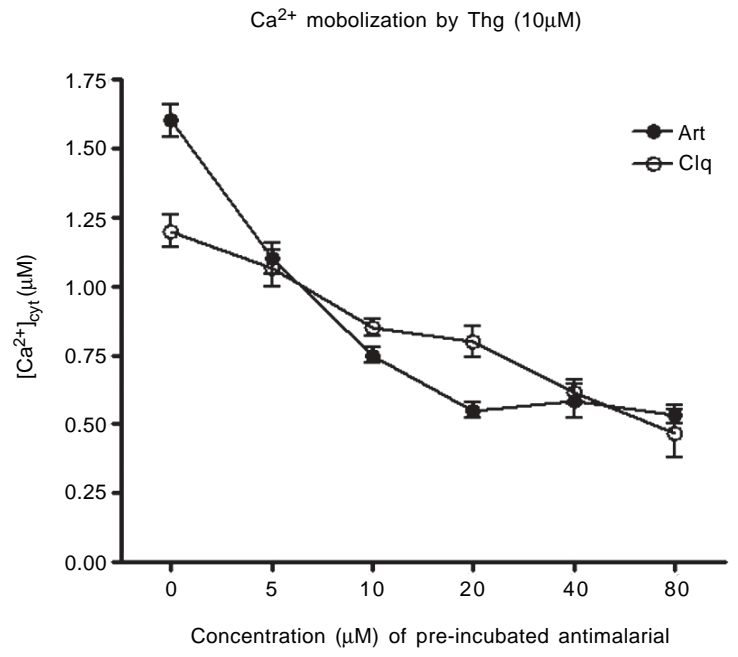

Fig. 5: effect of antimalarials drugs on calcium maintenance on endoplasmic reticulum in Plasmodium chabaudi. Isolated parasites $\left(10^{7}\right.$ cells $\mathrm{ml}^{-1}$ ) were loaded with calcium indicator Fluo-3 AM $(5 \mu \mathrm{M})$ for $50 \mathrm{~min}$ at $37^{\circ} \mathrm{C}$ and further incubation with different concentrations of antimalarials chloroquine (Clq) and artemisinin (Art) for $15 \mathrm{~min}$. The resting calcium present in ER was measured in spectrofluorimeter cuvette with addition $(10 \mu \mathrm{M})$ of $\mathrm{Ca}^{2+}$ ATPase inhibitor thapsigargin (Thg) $(\mathrm{n}=3)$.

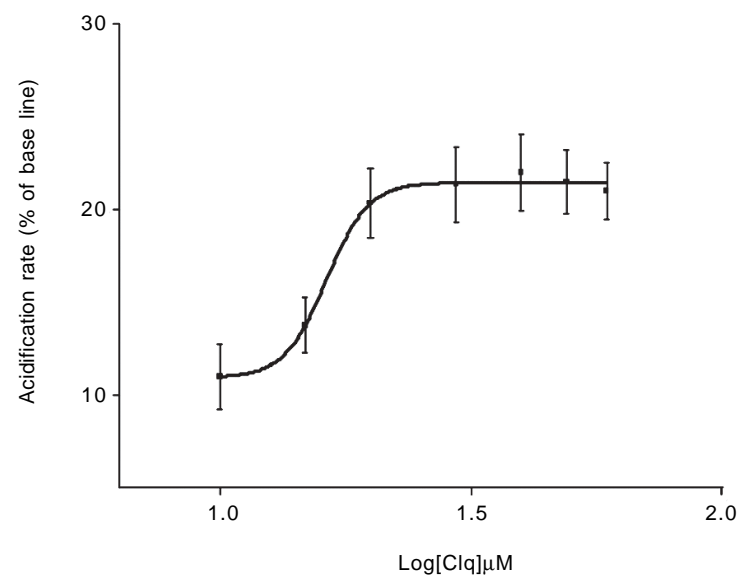

Fig. 6 : concentration-response curve for chloroquine-induced acidification rate in Plasmodium chabaudi. Exposure to chloroquine for $7 \mathrm{~min}$ with concentrations between $10 \mu \mathrm{M}$ and $60 \mu \mathrm{M}$. Concentration-response curve was calculated as the difference from baseline and the peak. $\mathrm{EC}_{50}$ calculated from this curve is $16.29 \mathrm{mM}(\mathrm{n}=3)$.

\section{DISCUSSION}

The antimalarial drug chloroquine is thought to accumulate in acidic compartments, although its mechanisms of action are controversial (Slater \& Cerami 1992, Dorn et al. 1995, Waller et al. 2003). The resistance to chloroquine observed in $P$. falciparum is dependent to mutations in specific transporter (PfCRT), by using heterologous expression Reeves et al. (2006) observed a increase of lysosomes acidification in mammalian cells expressing PfCRT, providing new information about acidification process and chloroquine resistance. 
We have previously shown that the acidic pool also functions as a $\mathrm{Ca}^{2+}$ store in permeabilized malaria parasites and that chloroquine causes $\mathrm{Ca}^{2+}$ release from this store (Passos \& Garcia 1998). In the present study, intact parasites were labeled with the calcium indicator, Fluo-3 AM to measure parasite cytosolic $\mathrm{Ca}^{2+}$ mobilization, and we also investigated the acidic pools in intact parasites within the RBC, using confocal microscopy.

The data in the present work indicate the existence of mechanisms for $\mathrm{H}^{+}$homeostasis in P. chabaudi parasites. The acidic vacuole in malaria parasite is the site of hemoglobin digestion and it is believed of drug action. In the rodent malaria parasite $P$. chabaudi the second messenger $\mathrm{IP}_{3}$ is known to induced-Ca ${ }^{2+}$ mobilization from this compartment (Passos \& Garcia 1998). These findings are of major significance, because they raise the possibility that chloroquine and artemisinin action in malaria parasites may involve alterations in ion homeostasis. This is especially important in view of our work showing that $\mathrm{IP}_{3}$-dependent $\mathrm{Ca}^{2+}$ signaling is involved in the progression of the malarial parasite cell cycle (Hotta et al. 2000, Gazarini et al. 2003, Beraldo et al. 2005).

By using confocal microscopy and analyzing $P$. chabaudi loaded with $\mathrm{AO}$ within the intact $\mathrm{RBC}$, we showed a $\mathrm{H}^{+}$mobilization, corresponding to a fluorescence decrease when V-type $\mathrm{H}^{+}$-ATPase was inhibited by bafilomycin (Fig. 1). Simultaneously, parasite cytosol fluorescence was transiently increased as the $\mathrm{AO}$ was released, thus indicating that cellular mechanisms were operating to restore cytosolic $\mathrm{pH}$ (Fig. 1B). Bafilomycin completely discharge the $\mathrm{AO}$ pool at $10 \mu \mathrm{M}$ (Fig. 1D) while $\mathrm{Ca}^{2+}$ release reach the maximal values at addition of $4 \mu \mathrm{M}$ of $\mathrm{H}^{+}$pump inhibitor (Fig. 4A).

The interaction of antimalarial artemisinin in $P$. falciparum was reported to occur through inhibition of PfATP6, a SERCA-type ATPase (Uhlemann et al. 2005). Our data shows the ability of both antimalarial in modifying the calcium and proton dynamics in $P$. chabaudi internal stores (Fig. 5).

We also addressed the metabolic response evoked by chloroquine with cytosensor microphysiometer (Fig. 6). These results showed that chloroquine stimulated a $\mathrm{H}^{+}$extrusion response with an $\mathrm{EC}_{50}$ of $16 \mu \mathrm{M}$ in $P$. chabaudi, using plasma membrane mechanisms to recover the intracellular pH (Saliba \& Kirk 1999).

Our data provide new information of acidic organelle physiology, the high concentration of bafilomycin required for complete reversion fluorescence from $\mathrm{AO}$, suggests a low density of $\mathrm{H}^{+}$pumps or susceptibility to the drug. However chloroquine action promoted a more extensively effect on parasite ion homeostasis than the specific $\mathrm{H}^{+}$pumps inhibitor bafilomycin. The micromolar concentration of antimalarial drugs required in our assay may represent the cell physiology differences between the Plasmodium species and we are search for extension of organelles capacity in ion maintenance.

The fact that $\mathrm{Ca}^{2+}$ antagonists block malaria parasite development is well known. In addition, reversal of chloroquine resistance in vitro by several $\mathrm{Ca}^{2+}$ antagonists such as verapamil has also been extensively reported (Deloron et al. 1991, Adovelande et al. 1998).
We have demonstrated that host melatonin activates parasite calcium signaling via the second messenger $\mathrm{IP}_{3}$, which appears to be important in the proliferation and maturation of the intraerythrocytic malaria parasites (Hotta et al. 2000). More recently, we also verify calcium mobilization with AFMK, a product of melatonin degradation in Plasmodium-infected erythrocytes (Budu et al. 2006). Finally, although the molecular mechanism of chloroquine and artemisinin action is not fully understood, its affect on calcium and proton activity indicates the importance in elucidate calcium homeostasis and signaling mechanisms on malarial parasites.

\section{ACKNOWLEDGEMENTS}

To Fapesp for funding CRSG and RPM. MLG received fellowship from Fapesp and CAS from CNPq.

\section{REFERENCES}

Adovelande J, Deleze J, Schrevel J 1998. Synergy between two calcium channel blockers, verapamil and fantofarone (SR33557), in reversing chloroquine resistance in Plasmodium falciparum. Biochem Pharmacol 55: 433-440.

Beraldo FH, Almeida FM, da Silva AM, Garcia CR 2005. Cyclic AMP and calcium interplay as second messengers in melatonin-dependent regulation of Plasmodium falciparum cell cycle. J Cell Biol 170: 551-557.

Biagini GA, Bray PG, Spiller DG, White MR, Ward SA. 2003. The digestive food vacuole of the malaria parasite is a dynamic intracellular $\mathrm{Ca}^{2+}$ store. J Biol Chem 278: 27910-27915.

Budu A, Peres R, Bueno VB, Catalani LH, Garcia CRS. 2007. N1-acetyl-N2-formyl-5-methoxykynuramine modulates the cell cycle of malaria parasites. J Pineal Research (in press).

Coppel RL, Culvenor JG, Bianco AE, Crewther PE, Stahl HD, Brown GV, Anders RF, Kemp DJ 1986. Variable antigen associated with the surface of erythrocytes infected with mature stages of Plasmodium falciparum. Mol Biochem Parasitol 20: 265-277.

Deloron P, Basco LK, Dubois B, Gaudin C, Clavier F, Le Bras J, Verdier F. 1991. In vitro and in vivo potentiation of chloroquine against malaria parasites by an enantiomer of amlodipine. Antimicrob Agents Chemother 35: 1338-1342.

Docampo R, Moreno SN. 2001. The acidocalcisome. Mol Biochem Parasitol 114: 151-159.

Dorn A, Stoffel R, Matile H, Bubendorf A, Ridley RG. 1995. Malarial haemozoin/beta-haematin supports haem polymerization in the absence of protein. Nature 374: 269-271.

Dzekunov SM, Ursos LM, Roepe PD 2000. Digestive vacuolar pH of intact intraerythrocytic $P$. falciparum either sensitive or resistant to chloroquine. Mol Biochem Parasitol 110: 107-124.

Farias SL, Gazarini ML, Melo RL, Hirata IY, Juliano MA, Juliano L, Garcia CR. 2005. Cysteine-protease activity elicited by $\mathrm{Ca}^{2+}$ stimulus in Plasmodium. Mol Biochem Parasitol 141: 71-79.

Garcia CR, Ann SE, Tavares ES, Dluzewski AR, Mason WT, Paiva FB. 1998. Acidic calcium pools in intraerythrocytic malaria parasites. Eur J Cell Biol 76: 133-138.

Garcia CR, Takeuschi M, Yoshioka K, Miyamoto H. 1997. Imaging Plasmodium falciparum-infected ghost and parasite by atomic force microscopy. J Struct Biol 119: 92-98.

Gazarini ML, Garcia CR 2004. The malaria parasite mitochon- 
drion senses cytosolic $\mathrm{Ca}^{2+}$ fluctuations. Biochem Biophys Res Commun 321: 138-144.

Gazarini ML, Thomas AP, Pozzan T, Garcia CR. 2003. Calcium signaling in a low calcium environment: how the intracellular malaria parasite solves the problem. J Cell Biol 161: 103-110.

Hayward R, Saliba KJ, Kirk K 2006. The pH of the digestive vacuole of Plasmodium falciparum is not associated with chloroquine resistance. J Cell Sci 119: 1016-1025.

Hotta CT, Gazarini ML, Beraldo FH, Varotti FP, Lopes C, Markus RP, Pozzan T, Garcia, C.R. 2000. Calcium-dependent modulation by melatonin of the circadian rhythm in malarial parasites. Nat Cell Biol 2: 466-468.

Howard RJ. 1982. Alterations in the surface membrane of red blood cells during malaria. Immunol Rev 61: 67-107.

Kirk K 2001. Membrane transport in the malaria-infected erythrocyte. Physiol Rev 81: 495-537.

Krungkrai J, Yuthavong Y. 1983. Enhanced $\mathrm{Ca}^{2+}$ uptake by mouse erythrocytes in malarial (Plasmodium berghei) infection. Mol Biochem Parasitol 7: 227-235.

Marchesini N, Luo S, Rodrigues CO, Moreno SN, Docampo R 2000. Acidocalcisomes and a vacuolar $\mathrm{H}^{+}$-pyrophosphatase in malaria parasites. Biochem J 347: 243-253.

McConnell HM, Owicki JC, Parce JW, Miller DL, Baxter GT, Wada HG, Pitchford S 1992. The cytosensor microphysiometer: biological applications of silicon technology. Science 257: 1906-1912.

McIntosh MT, Vaidya AB. 2002. Vacuolar type $\mathrm{H}^{+}$pumping pyrophosphatases of parasitic protozoa. Int J Parasitol 32: $1-14$.

Na BK, Shenai BR, Sijwali PS, Choe Y, Pandey KC, Singh A, Craik CS, Rosenthal PJ. 2004. Identification and biochemical characterization of vivapains, cysteine proteases of the malaria parasite Plasmodium vivax. Biochem J 378: 529-538.

Passos AP, Garcia CR. 1998. Inositol 1,4,5-trisphosphate induced $\mathrm{Ca}^{2+}$ release from chloroquine-sensitive and -insensitive intracellular stores in the intraerythrocytic stage of the malaria parasite P. chabaudi. Biochem Biophys Res Commun 245: $155-160$.
Reeves DC, Liebelt DA, Lakshmanan V, Roepe PD, Fidock DA, Akabas MH. 2006. Chloroquine-resistant isoforms of the Plasmodium falciparum chloroquine resistance transporter acidify lysosomal pH in HEK293 cells more than chloroquinesensitive isoforms. Mol Biochem Parasitol 150: 288-299.

Saliba KJ, Allen RJ, Zissis S, Bray PG, Ward SA, Kirk K. 2003. Acidification of the malaria parasite's digestive vacuole by a $\mathrm{H}^{+}$-ATPase and a $\mathrm{H}^{+}$-pyrophosphatase. J Biol Chem 278 : 5605-5612.

Saliba KJ, Kirk K. 1999. pH regulation in the intracellular malaria parasite, Plasmodium falciparum. $\mathrm{H}(+)$ extrusion via a v-type H(+)-ATPase. J Biol Chem 274: 33213-33219.

Scheibel LW, Colombani PM, Hess AD, Aikawa M, Atkinson CT, Milhous, WK 1987. Calcium and calmodulin antagonists inhibit human malaria parasites (Plasmodium falciparum): implications for drug design. Proc Natl Acad Sci USA 84: 7310-7314.

Slater AF, Cerami A. 1992. Inhibition by chloroquine of a novel haem polymerase enzyme activity in malaria trophozoites. Nature 355: 167-169.

Tanabe K, Mikkelsen RB, Wallach DF. 1982. Calcium transport of Plasmodium chabaudi-infected erythrocytes. J Cell Biol 93: 680-684.

Uhlemann AC, Cameron A, Eckstein-Ludwig U, Fischbarg J, Iserovich P, Zuniga FA, East M, Lee A, Brady L, Haynes RK, Krishna S. 2005. A single amino acid residue can determine the sensitivity of SERCAs to artemisinins. Nat Struct Mol Biol 12: 628-629.

Waller KL, Muhle RA, Ursos LM, Horrocks P, Verdier-Pinard D, Sidhu AB, Fujioka H, Roepe PD, Fidock DA. 2003. Chloroquine resistance modulated in vitro by expression levels of the Plasmodium falciparum chloroquine resistance transporter. J Biol Chem 278: 33593-33601.

Wasserman M, Vernot JP, Mendoza PM. 1990. Role of calcium and erythrocyte cytoskeleton phosphorylation in the invasion of Plasmodium falciparum. Parasitol Res 76: 681-688.

Yayon A, Cabantchik ZI, Ginsburg H. 1984. Identification of the acidic compartment of Plasmodium falciparum-infected human erythrocytes as the target of the antimalarial drug chloroquine. EMBO J 3: 2695-2700. 